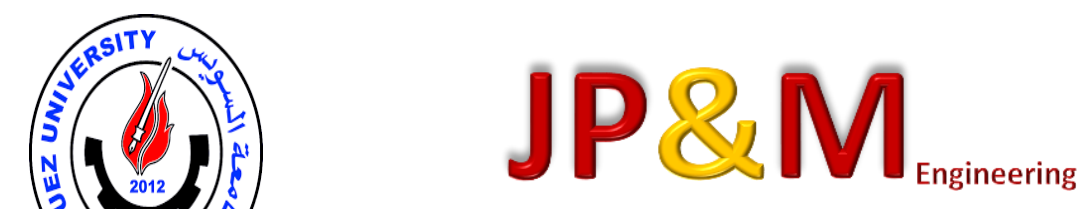

Journal of Petroleum and Mining Engineering

\title{
Industrial Application of Plant Crude Oil through Comparison of Heat Exchanger Network Synthesis Techniques
}

\author{
Shoaib, A. M., Emam, E. A., Osman, W. S.* \\ Department of Petroleum Refining and Petrochemical Engineering, Faculty of Petroleum and Mining Engineering, Suez University, Suez, \\ Egypt \\ *Corresponding author e-mail: Walaa.Osman@pme.suezuni.edu.eg
}

\section{Article Info}

Received 24 Nov. 2021

Revised 25 Dec. 2021

Accepted 13 Jan. 2022

\section{Keywords}

Heat exchanger network synthesis; heat integration; pinch technology; heuristics; mathematical programming models.

\begin{abstract}
Since the last few decades, global energy demand has steadily increased, creating a critical issue, particularly in the industrial sector. Energy conservation is an important issue in process design. Heat exchanger networks (HENs) synthesis have been the most studied in recent decades as its effect on energy recovery between process streams is significantly important. Pinch analysis and mathematical programming have been used for the synthesis of HENs. The proposed approaches can achieve the target of minimum utility consumption and develop networks to obtain a minimum number of heat exchange units. This paper presents a study to compare the performance of the heat exchanger network synthesized via pinch technology and mathematical programming for a crude oil plant. In addition, an application of a ready program like THEN is utilized to solve the problem. Based on the extracted data, the HEN is designed via the above-mentioned techniques, then, the results are analyzed and discussed in detail.
\end{abstract}

\section{Introduction}

Heat exchanger networks (HEN) have received a lot of attention as a way to improve heat recovery in industrial processes. In the industrial perceptive, the maximum energy recovery via synthesis of heat exchanger network (HEN), reveal significant reduction of cost. Process integration technology is considered as one of the most promising tools to recover the energy in the industry and it is an important phase in determining the cost of preliminary design.

Synthesis of HEN has been a well-researched topic over the past decades. Several studies and methodologies have been proposed to enable energy recovery between process streams. In addition, both the consumption of utilities and the number of heat transfer units can be minimized. Many research works were developed for optimal HEN synthesis using pinch technology and mathematical programming methods. Some recent research papers have used metaheuristic techniques such as Genetic Algorithms or Simulated Annealing, among others, to solve the HEN synthesis problem, with good results obtained but at a high computational exertion [1, 2].

Appropriate software packages will continue to be relevant in process optimization and in the pinch analysis of complex processes due to the mathematical and computing requirements involved. Isah et al., verified the effectiveness of heatintegration HINT by applying it to a case study that investigated the minimum area target, and then applying it to a crude distillation unit (CDU) [3]. A satisfactory solution was reached within $1 \%$ when compared to the existing solution to the minimum target area. The HINT package maximised heat recovery between hot and cold streams and then calculated the utility needed to maintain heat balance in heat exchanger networks (HENs). After the maximum energy recovery between all the hot streams and all the cold streams included in the HENs synthesised, a pinch analysis of the CDU plant revealed that both hot and cold utilities are still required. For the synthesis of the heat exchanger network, pinch analysis, and mathematical programming such as linear programming (LP) and mixed integer linear programming (MILP) with a transhipment model were used. In general, the mathematical programming-based techniques proved to be powerful for synthesizing HENs and generating alternative networks [3].

Pinch technology is a comprehensive methodology based on simple scientific principles that allows for the design of new plants with lower energy and capital costs, as well as the modification of existing processes to improve performance [4]. In addition, elaborations introduced the capital and total cost targets [5], extensions to total sites [6], as well as total sites integrating renewables [7].

Okechukwu and Azeez used the modified pinch technology, which is embedded in Aspen Hysys, and showed that it is a useful tool for optimising the area of a heat exchanger network [8]. The modified 
pinch tool Aspen Hysys version 8.6 was used to reduce the problem area of two heat exchanger networks. The results were compared to those of other researchers who solved the same problems using different methodologies. The classic pinch technique can still produce results that are as excellent as those produced using mathematical programming techniques in heat exchanger networks (HENs), according to a thorough evaluation of the results on area targeting on these problems using Aspen Hysys.

Tarighaleslamia, et al., analyzed Utility Heat Exchanger Networks (UEN) that are fastidiously intended to accomplish objectives for two Total Site Heat Integration strategies [9]. UEN designs show that most of the time it is unreasonable to accomplish Conventional Total Site (CTST) heat recovery (HR) and utility focuses for low temperature processes that need non-isothermal utilities. This impracticality arises from the need, on occasion, to match several process sources or sinks in sequential order to achieve total site objective. In the usual method, network relaxation can assist solve this problem, but if the network relaxation occurs on the side of the utility loop that restricts heat recovery $H R$, the site net utility consumption will increase. A redesigned targeting strategy is used in the recently established Unified Total Site method. The simplified UEN design compared to the CTST-based design indicated that HR targets are lower but more achievable to accomplish.

Many applications have been presented to the problem of designing heat exchanger networks. Pinch analysis was first used to design heat exchanger networks in the late 1970s, against the backdrop of the energy crisis [10-13]. Pinch Technology was widely known as a network heat exchanger design tool in the 1980 s, and it was observed that this innovation could save about $20-40 \%$ of industry energy bills. A good review on this technology had been presented by many authors [6, 14, 15].

Additionally, the pinch principle has been applied to other types of processes and areas. The analysis of emissions for total sites was explained [6, $14,16,17]$. Mass integration techniques, on the other hand, are based on the similarity between heat and mass transfer [18-20]. Water network synthesis [2126] and property integration [27-29] have been added to the process integration approach. Successful applications of process integration analysis were demonstrated for a fluidized catalytic cracking (FCC) plant [30], isothermal gas turbine [31], food industry [32], etc. In addition, as shown in the literature, Pinch technology supplies benefits far beyond oil-refining and petrochemicals $[27,32,33]$.

Later, Pinch oxygen analysis was introduced and combined with water by Zhelev and Bhaw, (1999) [34]. Meanwhile, Brown et al. $(2003,2005)$ presented an integrated approach which combine Pinch analysis, energy analysis, and optimisation techniques to identify energy targets in pulp and paper $[35,36]$. Marecha, (2004) have shared the feasibility rules to synthesize an optimum HEN [37]. Some heuristic rules have been proposed to complete the network based on decomposing it into two subnetworks; while Zhu et al., (1995) have introduced the idea of problem analysis into several blocks. Piece-wise stream composites in each block have similar profiles, and hot and cold streams are in energy balance [38]. Their work has been automated in 1998 in which a mixed integer linear programming (MILP) model and a simple mixed integer non-linear programming (MINLP) model were used to select the best set of matches and to determine the optimal split ratios [39].

Tangnanthanakan, and Siemanond established methods for multiperiod HEN synthesis that were both sequential and simultaneous [40]. HEN synthesis, HEN adaptation, and HEN integration are the three steps in the three-step sequential approach. The simultaneous method was implemented using a multiperiod simultaneous MINLP model that resolves in a single step. It has been demonstrated that the simultaneous technique outperforms the sequential three-step approach in terms of total annual cost

(TAC). Furthermore, the simultaneous MINLP model is particularly rigorous because there are no case studies that do not require an initial feasible solution. However, as the magnitude of the problem grows, the amount of time it takes to solve it grows exponentially. Then there is the technique of initialization.

Nishida et.al., introduced an evolutionary algorithmic approach to the systematic synthesis of minimal-cost networks of exchangers, heaters, and coolers [41]. Aguilera and Marchetti proposed a systematic technique for heat-exchanger network online optimization and control, which is distinguished by a two-level control structure, one for the fixed configuration control system and the other for a supervisor online optimizer [42]. The outcomes of applying the dual approach temperature method (DAT) to the industrial ethylene product recovery and separation process were presented by Chang and Guo (2005) [43]. To extract process information for designing the heat exchange network, the complete process, including the refrigeration system, was simulated.

The aim of this study is comparing the efficiency of the heat exchanger network synthesized by different techniques. The first technique is based on pinch technology that uses heuristics rules for constructing the HEN. The second technique is based on an optimization mathematical program algorithm that is based on solving the HENs problem in two sequential steps: targeting and designing the network, El-Halwagy, (1997) [19]. While the third technique, is the use of a ready program like THEN to solve the problem. An industrial case study taken from an Egyptian Petroleum Refining Company has been introduced to illustrate the comparison study.

\section{Selected Algorithms}

The first algorithm used for comparison is based on the work proposed mainly by Linnhoff and Hindmarch, (1983) and have been developed in many other publications $[15,44]$. This work is based on the pinch design method which suggests that no heat must be transferred across the pinch to reach the maximum energy recovery. The network design in such technique is divided into two separate problems; namely one above the pinch and the other is below the pinch. Such pinch technology-based method is 
based on applying some heuristic rules to construct the HEN efficiently [15].

The second algorithm used for comparison is based on the mixed integer nonlinear program adapted from El-Halwagi, (1997) [19]. That program is based on synthesizing the HEN in two sequential steps. First, the minimum utility requirements is evaluated, then the network achieving the minimum number of units is constructed. The different equations used to achieve that target is shown below. Lingo optimization program is used to solve such optimization problem.

Minimizing utility requirements:

$$
\begin{aligned}
& \operatorname{Min}=\mathrm{Hu} \\
& \operatorname{Min}=\sum_{k=\text { int }}^{k=1} H u \mathrm{k}
\end{aligned}
$$

Subject to

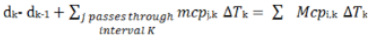

$$
\begin{aligned}
& M_{c p j} \geq 0 \quad j=1,2, \ldots \ldots \ldots \ldots \ldots . . N C \\
& \mathrm{~K} \geq 0 \quad \mathrm{k}=1,2, \ldots \ldots \ldots \ldots \ldots \mathrm{N}_{\text {int }}
\end{aligned}
$$

\section{Minimizing number of units:}

The subnetworks will be denoted by SNm, where $m=1,2$ (above and below the pinch respectively).

$H_{m}=\left\{i \mid i \in H\right.$, stream i exists in $\left.\mathrm{SN}_{m}\right\}$

$\mathrm{C}_{\mathrm{m}}=\left\{\mathrm{j} \mid \mathrm{j} \in \mathrm{C}\right.$, stream $\mathrm{j}$ exists in $\left.\mathrm{SN}_{\mathrm{m}}\right\}$

$H_{m, k}=\left\{i \mid i \in \mathrm{Hm}\right.$, stream i exists in interval $\left.k \in S N_{m}\right\}$

$C_{m, k}=\left\{j \mid j \in C m\right.$, stream $j$ exists in interval $\left.k \in S N_{m}\right\}$

For a hot stream $\mathrm{i}$

$$
\mathrm{d}_{\mathrm{i}, \mathrm{k}-}-\mathrm{d}_{\mathrm{i}, \mathrm{k}-1}+\sum_{j=C_{m, \mathrm{k}}}^{\mathrm{k}_{\mathrm{k}}} w_{\mathrm{i}, \mathrm{j}, \mathrm{k}}=w_{\mathrm{i}, \mathrm{k}}
$$

The heat exchanged between any two streams, within any subnetwork, is bounded by the smaller of the two loads. Therefore, the upper limit of heat exchangeable between streams $i$ and $j$ in $\mathrm{SNm}$ is given by:

$$
\begin{aligned}
& \mathrm{U}_{\mathrm{i}, \mathrm{j}, \mathrm{m}}=\min \left\{\sum_{k \in S N_{\mathrm{m}}} W_{\mathrm{i}, \mathrm{k}}, \sum_{k \in S N_{\mathrm{m}}} W_{\mathrm{j}, \mathrm{k}}\right\} \\
& \sum_{k \in S N_{m}} W_{\mathrm{i}, \mathrm{j}, \mathrm{k}}-U_{\mathrm{i}, \mathrm{j}, \mathrm{m}} \leq 0 \\
& \mathrm{i} \in \mathrm{H}_{\mathrm{m}}, \mathrm{j} \in \mathrm{C}_{\mathrm{m}}, \mathrm{m}=1,2
\end{aligned}
$$

where $W_{i, j, k}$ denotes the heat exchanged between the $i^{\text {th }}$ hot stream and the $j^{\text {th }}$ cold stream in the $k^{\text {th }}$ interval.

$$
\text { minimize } \sum_{m=1,2} \sum_{i \in H \mathrm{~m}} \sum_{j \in C \mathrm{~m}} E_{\mathrm{i}, \mathrm{j}, \mathrm{m}}
$$

subject to the following:

Heat balance for each hot stream around intervals:

$$
\begin{aligned}
& \mathrm{d}_{\mathrm{i}, \mathrm{k}}-\mathrm{d}_{\mathrm{i}, \mathrm{k}-1}+\sum_{j=C_{\mathrm{m}, \mathrm{k}}}^{\mathrm{j}} w_{\mathrm{i}, \mathrm{k}, \mathrm{k}}=w_{\mathrm{i}, \mathrm{k}} \\
& \mathrm{i} \in \mathrm{H}_{\mathrm{m}, \mathrm{k}}, \mathrm{k} \in \mathrm{SN} \mathrm{m}, \mathrm{m}=1,2
\end{aligned}
$$

Heat balance for each cold stream around composition intervals:

$$
j \in C_{m}, k, k \in S N_{m}, m=1,2
$$

Matching of loads:

$$
\begin{aligned}
& \sum_{k \in S N_{m}} w_{\mathrm{i}, \mathrm{j}, \mathrm{k}}-U_{\mathrm{i}, \mathrm{j}, \mathrm{m}} E_{\mathrm{j}, \mathrm{m}} \leq 0 \\
& \mathrm{i} \in \mathrm{H}_{\mathrm{m}}, \mathrm{j} \in \mathrm{C}_{\mathrm{m}}, \mathrm{m}=1,2 \\
& \mathrm{E}_{\mathrm{i}, \mathrm{j}, \mathrm{m}}=0 / 1 \quad \mathrm{i} \in \mathrm{H}_{\mathrm{m}, \mathrm{k}}, \mathrm{j} \in \mathrm{C}_{\mathrm{m}, \mathrm{k}}, \mathrm{m}=1,2
\end{aligned}
$$

The third technique used is the use of a ready program package that depends on just introducing the data, and the network is developed without any engineering experience. The program package used for comparison in that work is called THEN. In the present work, the different described techniques will be applied to design heat exchanger network. The introduced case study is an industrial application taken from an Egyptian Petroleum Refining Company.

\section{Case Study}

The data given are for a crude oil distillation unit. It has one cold stream (the crude oil stream) and five hot steams (the distillate products). The flowsheet of the crude distillation unit and full data of the unit are given in Figure 1 and Table 1 respectively.

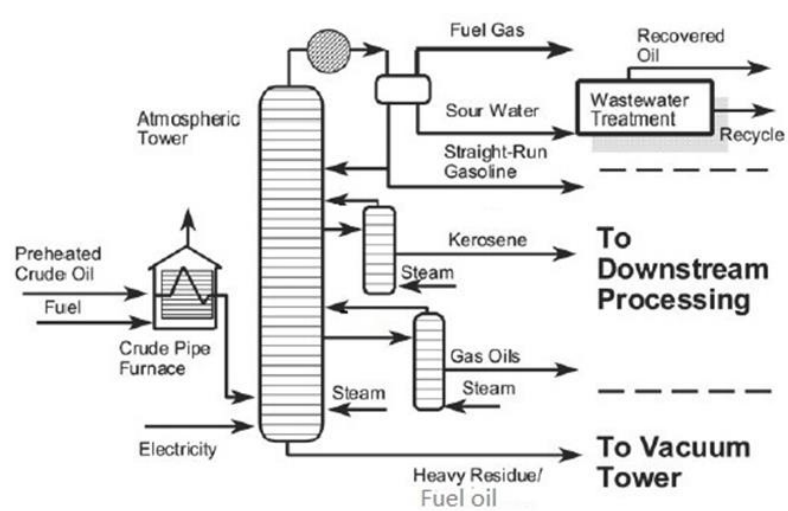

Figure 1: Crude oil distillation unit flowsheet.

$\sum_{i=H_{\mathrm{m}, \mathrm{k}}} w_{\mathrm{i}, \mathrm{j}, \mathrm{k}}=w_{\mathrm{j}, \mathrm{k}}$ 
Table 1: Data for crude oil case study.

\begin{tabular}{|l|l|l|l|l|}
\hline & & Supply $\left.T .{ }^{\circ} \mathrm{C}\right)$ & Target $\left.T .{ }^{\circ} \mathrm{C}\right)$ & MCp $\left(\mathrm{Kw} /{ }^{\circ} \mathrm{C}\right)$ \\
\hline $\mathrm{H} 1$ & T.P. A. & 188 & 121 & 59 \\
\hline $\mathrm{H} 2$ & Kerosene & 166 & 40 & 13.8 \\
\hline $\mathrm{H} 3$ & Gas oil & 260 & 60 & 14.5 \\
\hline H4 & Fuel oil & 317 & 80 & 31.11 \\
\hline H5 & B.P. A. & 275 & 132 & 38 \\
\hline C1 & Crude oil & 15 & 320 & 72.36 \\
\hline
\end{tabular}

T.P.A.: the top product pump around

B.P.A.: the bottom product pump around

\section{The cost data:}

1) Capital cost data:

$\$=30000+750 \mathrm{~A} 0.8$

Where $A$ is the area of heat exchanger, $\mathrm{m} 2$

Plant lifetime 5 yr

Rate of interest $10 \%$
2) Working cost data:

Annual cost of hot utility unit is 120,000 (\$/MW.yr)

Annual cost of cold utility unit is 30,000 (\$/MW.yr)

Net heat available $=21398.9 \mathrm{KW}$

Net heat needed $=22069.8 \mathrm{KW}$

Applying the first technique that is based on pinch technology resulted in the network shown in Figure 2 , while the network design resulting from the MINLP is shown in Figure 3. Finally, the ready THEN program was applied to the case study to construct the network shown in Figure 4.

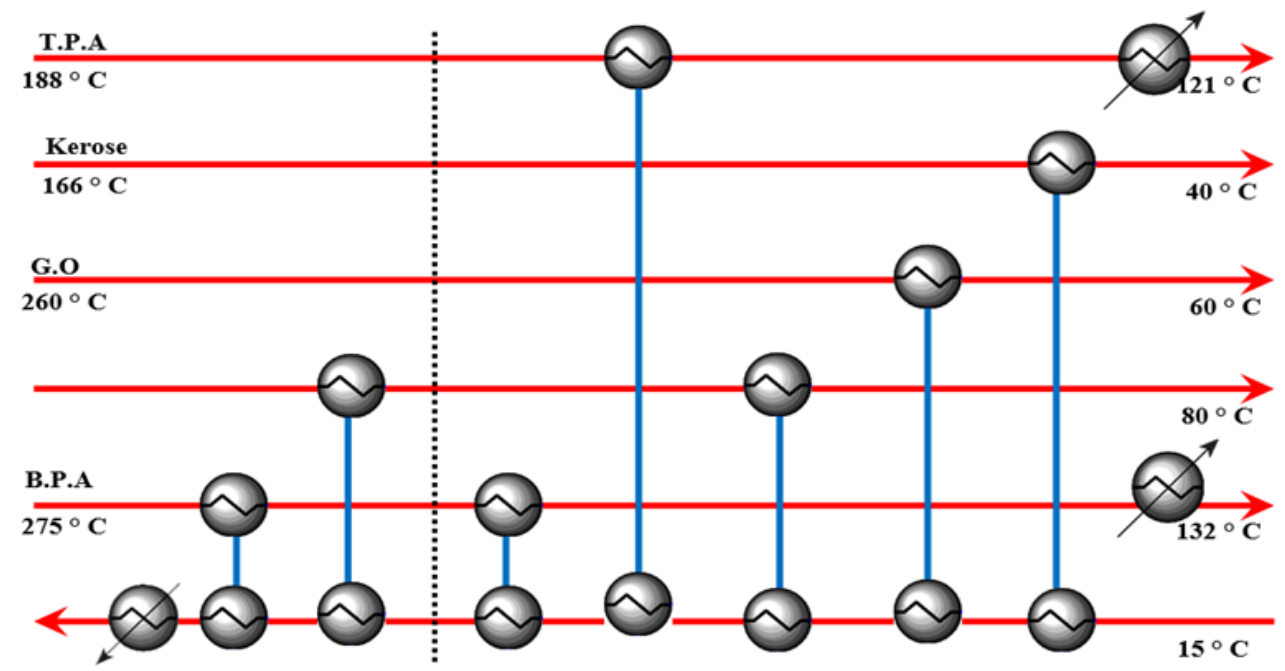

Figure 2: Network design using pinch design method. 


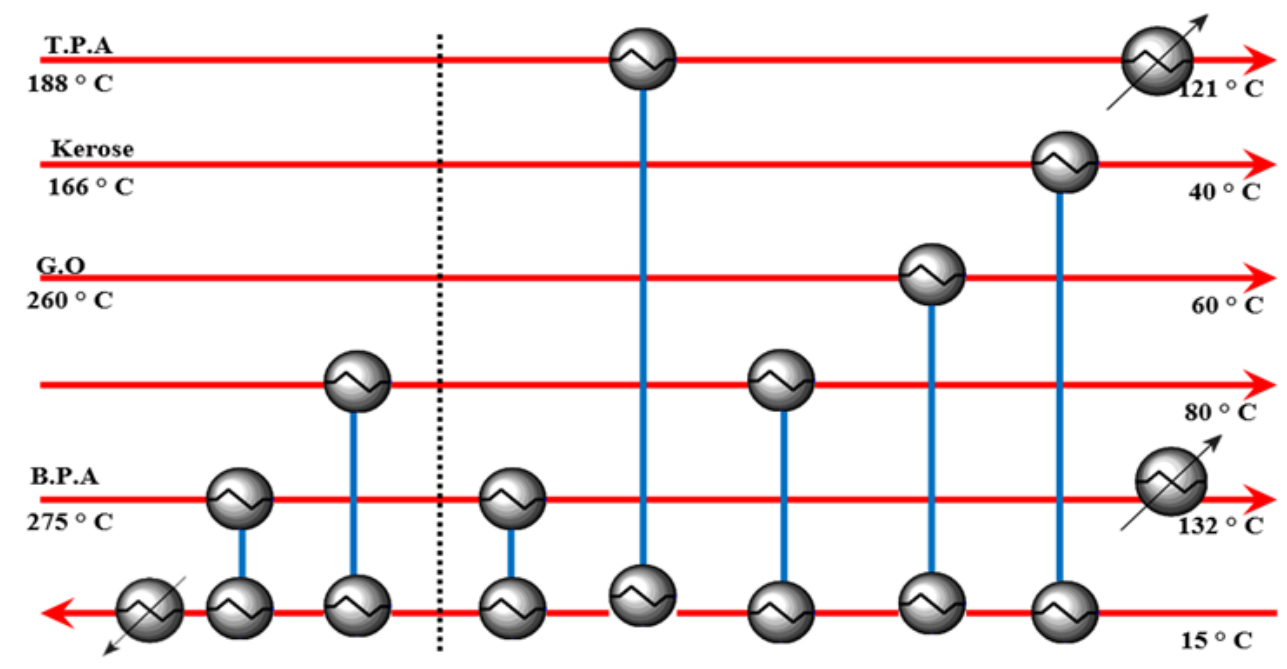

Figure 3: Network design using MINLP.

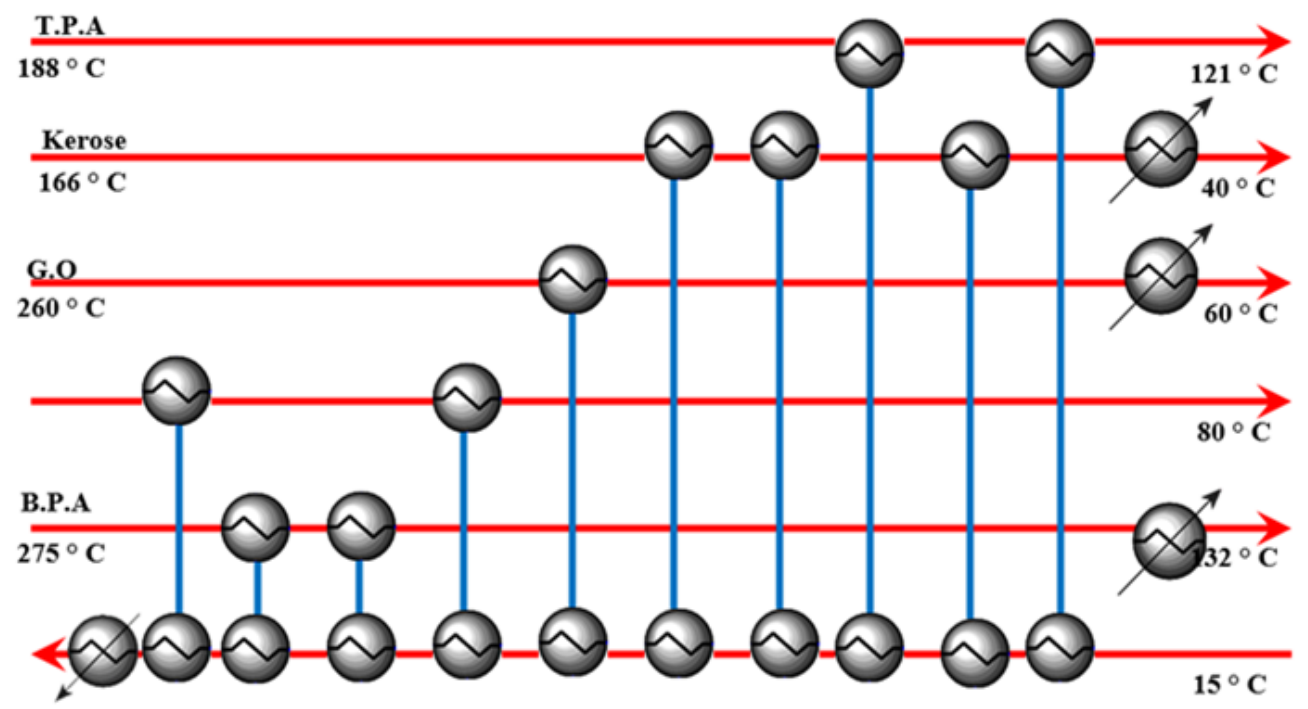

Figure 4: Network design using THEN program.

\section{Results and Discussion}

It is obvious that different networks have resulted from the application of alternative methods.
Table 2 indicates a comparison between the three networks in the critical variables which directly affect the efficiency and cost of the network.

Table 2: Comparison between alternative results.

\begin{tabular}{|l|l|l|l|}
\hline Variables & Figure 2 & Figure 1 & Figure 3 \\
\hline $\begin{array}{l}\text { Total Hot Utility Duty (Hu) } \\
\text { KW }\end{array}$ & 3807.33 & 3808 & 3840.406 \\
\hline $\begin{array}{l}\text { Total Cold Utility Duty (Cu) } \\
\text { KW }\end{array}$ & 3136.4 & 3137 & 3051.5 \\
\hline No. of Hot Utility Needed & One & One & One \\
\hline No. of Cold Utility Needed & Two & Two & Three \\
\hline No. of H.Es Used & Seven & Seven & Ten \\
\hline Total Area Needed, $\mathbf{m}^{\mathbf{2}}$ & 5312 & 5312 & 5513.086 \\
\hline
\end{tabular}




\begin{tabular}{|l|l|l|l|}
\hline Capital Cost for II H.Es , \$ & $926.585^{*} 10^{3}$ & $926.585^{*} 10^{3}$ & $948.195^{*} 10^{3}$ \\
\hline Annual Operating Cost, \$/yr & $550.97^{*} 10^{3}$ & $551.07^{*} 10^{3}$ & $552.394^{*} 10^{3}$ \\
\hline
\end{tabular}

First of all, it is noted that the number of units is the same in the networks constructed by pinch technology and mathematical programming technique (networks 1 and 2 respectively) which is equivalent to the minimum number of units, while applying a ready program (network 3 ) resulted in an extra number of units which exceeds the unit target by four units. The existence of loops in network 3 is the main cause of the extra units. So, such loops should be broken in order to achieve the unit targets. Achieving the minimum number of units has a benefit of reducing the fixed cost in addition to improving the operability of the network. From the viewpoint of the number of hot and cold utilities, it is found that they are the same in both networks 1 and 2, while they are higher in network 3 . It is worth noting that networks 1 and 2 achieved the utility targets while network 3 relatively exceeds the target. The net result is an increase in the total cost of network 3 compared to networks 1 and 2 . This means that a ready program couldn't achieve the optimal or near optimal network, but it just facilitates the network design for low experience operators. The network designed by a ready program package should be improved by a high experience designer.

Comparing the networks designed by pinch technology and mathematical optimization program, it is found that they have nearly the same construction. Both the algorithms have been applied successfully and evolved in reasonable results. However, results obtained from optimization program are more precise. Mathematical programming technique is more practical for networks having high number of streams, while pinch technology is inconvenient when the number of streams increase. It is worth to mention that the MINLP used could result in thousands of other networks by adding additional constraints that forbid the existing ones. This could be very important when adding additional requirements such as maximum controllability, better operability, and so on. On the other hand, pinch technology is suitable for designers having low computer experience and less computational effort.

\section{Conclusions}

A crude oil plant has been introduced and solved using alternative techniques, pinch technology, an optimization model and THEN program. Results showed that the networks achieved using pinch technology and mathematical programming methods are almost the same, while applying THEN program resulted in less reasonable results but with less effort.

Mathematical programming techniques could result in thousands of other networks by adding additional constraints to increase other requirements related to the plant, while pinch technology which is based on heuristics results in almost one network. That could be taken as a drawback of that technique.

\section{Acknowledgements}

The feedback of Prof. Mahmoud El-Halwagi, and Prof. Dominic Foo Chwan Yee is gratefully acknowledged.

$\begin{array}{cl}\text { Nomenclature } \\ \mathrm{Hu} & \text { Hot utility } \\ \mathrm{WU}_{\mathrm{i}, \mathrm{j}, \mathrm{k}}: & \text { Hot utility in interval } \mathrm{k} \\ \mathrm{i} & \text { The heat transferred from hot } \\ \mathrm{J} & \text { number of hot streams } \mathrm{i} \text { no cold stream } \mathrm{j} \\ \mathrm{K} & \text { number of cold streams } \\ \mathrm{E}_{\mathrm{i}, \mathrm{j}, \mathrm{m}} & \text { the heat exchangers between hot } \\ & \text { stream } \mathrm{i} \text { and cold stream } \mathrm{j} \text { in } \\ & \text { subnetwork } \mathrm{m} \\ \mathrm{SN} \mathrm{N}_{\mathrm{m}} & \text { subnetworks } \\ \mathrm{m}=1 & \text { above pinch } \\ \mathrm{m}=2 & \text { below pinch } \\ \mathrm{d}_{\mathrm{i}, \mathrm{k}} & \text { the heat transferred from interval } \\ \mathrm{M}_{\mathrm{cp}} & \text { h-1 to } \mathrm{k}\end{array}$

\section{Funding sources}

This research received no external funding.

\section{Conflicts of interest}

There are no conflicts to declare

\section{Reference}

1. M.A.S.S. Ravagnani, A.P.S., P.A. Arroyo, A.A. Constantino, Heat exchanger network synthesis and optimisation using genetic algorithm. Applied Thermal Engineering 2005. 25: p. 1003-1017.

2. Mees, M.L.A., Convergence of an annealing algorithm. Mathematical Programming 1986. 34: p. 111-124.

3. Abubakar Isah, O.A., Danjuma Kolo, Ishaq Mohammed, and Kolawole Onifade, "Pinch analysis of crude distillation unit using the HINT software and comparison with nonlinear programming technique" https://doi.org/10.22541/au.157990356.63045554 in Authorea May 5, 2020.

4. Linnhoff B. and Hindmarsh E., "The pinch design method for heat exchangers networks". Chemical and Engineering Science, 1983. 38(5): p. 745-763.

5. Linnhoff B. and Ahmad S., "Cost optimum heat exchanger networks-1. Minimum energy and capiltal 
using simple models for capital cost". Comp Chem Engng, , 1990,. 14: p. 729-750.

6. Klemeš J., D.V.R., Raissi K., Perry S. J. and Puigjaner L.,, "Targeting and design methodology for reduction of fuel, power and $\mathrm{CO} 2$ on total sites". Applied Thermal Engineering, 1997,. 17 (8/10): p. 993-1003.

7. Perry S., K.J.a.B.I., "Integrating waste and renewable energy to reduce the CFP of locally integrated energy sectors". Energy 2008. 33: p. 1489-1497.

8. Okechukwu O. J., a.A.O.S. "Area Targeting of Heat Exchanger Network (Hen) Using A Modified Pinch Technique" in 2nd International Conference on Science and Sustainable Development. 2018.

9. Tarighaleslami A. H., T.G.W., Martin J. Atkins, Michael R.W. Walmsley, James R. Neale, " A Comparison of Utility Heat Exchanger Network Synthesis for Total Site Heat Integration Methods". Chemical Engineering Transactions, 2017. 61

10. Linnhoff B. and Flower J. R., "Synthesis of heat exchanger networks: I. systematic generation of energy optimal networks". AIChE Journal, 1978. 24 (4): p. 633-642.

11. Linnhoff B., M.D.R.a.W.I., "Understanding heat exchanger networks". Computers \& Chemical. Engineering, 1979. 3 (1-4) p. 295-302.

12. Linnhoff B., T.D.W., Boland D., Hewitt G. F., Thomas B. E. A., Guy A. R., and Marsland R. H., , "A user guide to process integration for the efficient use of energy". last edition 1994, ed. 1982, IChemE, Rugby, UK.

13. R., S., "Chemical process design" 1995, New York.: McGraw Hill.

14. Hassan M., H.D., "Harbingers of hope in the transition to sustainable societies: beyond gloom and doom to action", in CHISA 2008 Proceedings, 2008, p. Prague, ČSCHI, 1089-1090.

15. Shenoy, U.V., "Heat exchanger network synthesis: the pinch technology-based approach"Gulf publishing Co, Houston. 1995.

16. B., D.V.R.a.L., "Total site targets for fuel, co-generation, emissions and cooling" Computers \& Chemical Engineering, 1993. 17.

17. Cirlly D. and Zhelev T., "Current trends in emissions targeting and planning an application of $\mathrm{CO} 2$ emissions pinch analysis to the Irish electricity generation sector". Energy 2008 33: p. 1498-1507.

18. El-Halwagi M. M., “Process integration”. 2006, Amsterdam.: Elsevier.

19. M., E.-H.M., "Pollution prevention through process integration: systematic design tools". Academic Press, San Diego., 1997

20. V., E.-H.M.M.a.M., "Synthesis of mass exchange networks" AIChE Journal, 1989. 35 (8): p. 1233-1244.

21. El-Halwagi M. M., G.F., and Harell D., "Rigorous graphical targeting for resource conservation via material recycle/reuse networks". Ind. Eng. Chem. Res., 2003. 42: p. 4319-4328.

22. Foo D. C. Y., M.Z.A.a.T.Y.L., "Use cascade analysis to optimize water networks" Chem. Eng. Prog. , 2006a. 102: p. 45-52.

23. Manan Z. A., T.Y.L.a.F.D.C.Y., "Targeting the minimum water flowrate using water cascade analysis technique". AIChE Journal, 2004,. 50: p. 3169-3183.

24. Ng D. K. S., F.D.C.Y.a.T.R.R., "Targeting for total water network" Ind. Eng. Chem. Res., ,2007. 46: p. 9107-9125.
25. V., P.R.a.S.U., "Targeting and design of water networks for fixed flowrate and fixed contaminant load operations". Chem. Eng. Sci. , 2005. 60: p. 255-268.

26. Wang Y. P. and Smith, R., "Wastewater minimisation" Chemical Engineering Science 1994. 49(7): p. 981-1006.

27. Ataei A., P.M.H., Parand R. and Tahouni N., "Application of an optimum design of cooling water system by regeneration concept and pinch technology for water and energy conservation" Applied Sciences, ,2009. 9(10): p. 1847-1858.

28. Foo D. C. Y., K.V., El-Halwagi M. M. and Manan Z. A.,, "Surplus diagram and cascade analysis technique for targeting property-based material reuse network". Chem. Eng. Sci. , 2006b,. 61: p. 2626-2642.

29. Kazantzi V., a.E.-H.M.M., “Targeting material reuse via property integration". Chem. Eng. Prog. , 2005,. 101: p. 28-37.

30. Badr Abdullah Al-Riyami, J.K., Simon Perry, Heat integration retrofit analysi of a heat exchanger network of a fluid catalytic cracking plant. Applied Thermal Engineering, 2001. 21: p. 1449-1487.

31. Kalitventzeff B., D.M.-N.a.M.F., "Process integration techniques in the development of new energy technologies: application to isothermal gas turbine", in CHISA'98 / 1st Conference PRES'98, . 1998. p. Prague, F3.1 [447].

32. Klemeš J., K.G.a.N.N. "Application of pinch-technology in food industry”. in CHISA'98 / 1st Conference PRES'98, . 1998.

33. Pleşu V., K.J.a.G.M. "Applications of process integration in romanian oil refining and petrochemical industry". in CHISA'98 / 1st Conference PRES. 1998.

34. Zhelev T. and Bhaw N. "Combined water-oxygen pinch analysis for better wastewater treatment management". in PRES'99 Proceedings, ed. F. Friedler and J. Klemeš, . 1999.

35. Brown D., M.F.a.P.J., "Cogeneration system design methodology in pulp and paper process", in 53th CSChE 2003 with PRES' 03,. 2003: Hamilton, Canada, 343.

36. Brown D., M.F.a.P.J., "A dual representation for targeting process retrofit application to a pulp and paper process". Applied Thermal Engineering 2005,. 25 (7): p. 10671082.

37. F., M., "4. Heat exchangers network synthesis". Energétique Avancée - Process integration, 2004. v26.9.

38. Zhu X. X., N.B.K.O., Roach J. R. and Wood R. M., "A method for automated heat exchanger synthesis using block decomposition and non-linear optimization". Chem. Eng. Res. and Des.,, 1995. 73(A): p. 919-930.

39. Zhu X. X., N.B.K.O., Roach J. R. and Wood R. M., "Automated design method for heat exchanger network using block decomposition and heuristic rules". computer and chemical engineering, 1998. 21 (10): p. 1095-1104.

40. Tangnanthanakan P., a.S.K., "Comparison of Sequential and Simultaneous Approaches for Multiperiod Heat Exchanger Network Synthesis and Application for Crude Preheat Train". Chemical Engineering Transactions, 2014. 39.

41. Nishida N., L.Y.A., Lapidous N.,, "A Simple and practical approach to the optimal synthesis of heat exchanger networks". AlChE Journal, 1976. 23: p. 77-93. 
42. L., A.N.a.M.J., "Optimizing and controlling the operation of heat exchanger networks". AIChE Journal, 1998. 44: p. 1090-1104

43. J., C.H.a.G.J., "Heat exchange network design for an ethylene process using dual temperature approach". Science and Engineering, 2005. 8 (4),: p. 283-290.

44. R., A.S.a.S., "Targets and design for minimum number of shells in heat exchanger networks". Chem. Eng. Res. Des., 1989. 67 (5): p. 481-494. 